\title{
O ensino de pensamento computacional por meio de jogos desplugados e olimpíadas científicas: um relato de experiência nos anos finais do ensino fundamental
}

\author{
Alexandre F. Lopes ${ }^{1}$, Thalia S. Santana ${ }^{1}$, Adriano H. Braga ${ }^{1}$ \\ ${ }^{1}$ Instituto Federal Goiano - Campus Ceres (IF GOIANO) \\ Caixa Postal 51 - 76.300-000 - Ceres - GO - Brasil \\ \{alexandre9999lopes, thaliassantana15\}@gmail.com, \\ adriano.braga@ifgoiano.edu.br
}

\begin{abstract}
This article reports the experience of a computational thinking course for students in the 9th grade of elementary school. The strategy consists of using elements from unplugged games and scientific olympics to promote computational thinking, in addition to providing opportunities for participation in the Brazilian Informatics Olympiad (OBI). The results obtained suggest the potential of gamification in addition to the good classification of participants in the XXI OBI.
\end{abstract}

Resumo. Este artigo relata a experiência de um curso de pensamento computacional para alunos do $9^{\circ}$ ano do ensino fundamental. A estratégia consiste em utilizar elementos de jogos desplugados e olimpíadas científicas para promoção de pensamento computacional, além de oportunizar a participação na Olimpíada Brasileira de Informática (OBI). Os resultados obtidos sugerem o potencial da gamificação além de boa classificação dos participantes na XXI OBI.

\section{Introdução}

O pensamento computacional refere-se a uma habilidade imprescindível tanto quanto a leitura, escrita e aritmética (WING, 2006), a fim de possibilitar uma nova abordagem para resolução de problemas por meio de uma abstração computacional. Este conceito trata-se de uma nova forma de organizar o pensamento, capaz de proporcionar formação ampla para as mais diversas áreas de atuação, de maneira interdisciplinar e promovendo autonomia aos sujeitos no aprendizado tecnológico, para muito além da computação (WERLICH; KEMCZINSKI; GASPARINI, 2018).

$\mathrm{O}$ ensino de pensamento computacional como disciplina é presente em vários países, como no caso da Alemanha, Finlândia, Argentina e Coréia do Sul, com consequente popularização em iniciativas brasileiras (BRACKMANN, 2017). Desta forma, organizações e sociedades científicas como a Sociedade Brasileira de Computação (SBC), levantam a importância de sua inserção desde a educação básica como um dos eixos do ensino de computação (SBC, 2017), visto compreender e colaborar para o desenvolvimento de todas as competências estabelecidas pela Base Nacional Comum Curricular (RIBEIRO, 2019).

Neste contexto, estudos vêm sendo realizados em prol da ampliação do ensino deste tema combinado a conceitos de computação, inclusive a partir dos primeiros anos 
da vida escolar. A exemplo disso, trabalhos como os de Schoeffel et al. (2015), Aono et al. (2017), Martin et al. (2018), Oliveira, Aranha Junior e Barradas Filho (2019) relatam sobre pensamento computacional com envolvimento do ensino fundamental. Além disso, existem esforços da própria SBC para a disseminação de pensamento computacional no Brasil que abrangem todos os níveis de escolaridade, como o exemplo da realização da Olimpíada Brasileira de Informática (OBI) (BRACKMANN, 2017).

Assim, o presente trabalho tem como intuito apresentar um relato de experiência do ensino de pensamento computacional nos anos finais do ensino fundamental, com ênfase em jogos desplugados e preparação para olimpíadas científicas em informática. Além da introdução, o artigo está organizado do seguinte modo: a Seção 2 apresenta a metodologia empregada durante o planejamento e execução das aulas; a Seção 3 demonstra os resultados e discussões relativos ao curso e sua avaliação, e por fim, na Seção 4, as considerações finais, seguidas das referências bibliográficas.

\section{Materiais e Métodos}

A execução do curso teve início em abril de 2019, seguindo até meados de agosto do mesmo ano, totalizando 20 horas/aula, sendo 10 encontros de 2 horas/aula cada um. As aulas foram ministradas pela equipe executora do projeto, composta por um docente orientador e dois bacharelandos em Sistemas de Informação do Campus Ceres do Instituto Federal Goiano. O público-alvo tratou-se de estudantes de uma turma de $9^{\circ}$ ano do ensino fundamental regular do turno matutino da escola pública Colégio Estadual Câmara Filho da cidade de Rialma-GO. Os encontros foram obrigatórios aos acadêmicos matriculados e aconteceram semanalmente, com datas e horários distintos, definidos previamente entre a equipe executora do projeto e a direção da escola, de forma concomitante ao andamento das disciplinas regulares dos discentes.

A fim de estabelecer os temas abordados durante as aulas, definiu-se a ementa do curso oferecido, fundamentado principalmente na obra de Martins (2011) alinhada à abordagem desplugada proposta por Bell (2012). O conteúdo programático envolveu conceitos como raciocínio lógico-matemático, desafios lógicos e aprendizado de pensamento computacional por intermédio de exercícios de olimpíadas científicas de informática. Dentre as temáticas da olimpíada, tópicos como Ordenação Linear, Quadrática e Agrupamentos foram trabalhados, inclusive por meio de jogos desplugados: dinâmicas alusivas ao tópico trabalhado com elementos de jogabilidade e participação ativa dos educandos, a exemplo de uma simulação de um estacionamento de carros, elemento de um dos exercícios tratados na competição. Ademais, os encontros também abrangeram a participação na Modalidade Iniciação da XXI OBI.

Visando promover o engajamento dos discentes no decorrer das aulas, utilizou-se a estratégia da gamificação, aplicada por Brum (2017), com o intuito de cativar os participantes por meio de desafios constantes e premiações. Portanto, no início da execução definiu-se atividades que seriam convertidas em pontos e que ao final do projeto, as maiores pontuações seriam premiadas (Tabela 1). Em casos de não participação ou ausência da entrega dos itens da tabela, nenhum ponto era atribuído.

Ademais, combinada ao elemento anterior, adotou-se uma metodologia de trabalho colaborativo para a execução das aulas. A cada vez que um novo conteúdo era 
apresentado, resolvia-se um exemplo passo a passo com os estudantes, e em seguida, foram propostos de dois a quatro exercícios para que os alunos colocassem em prática o conceito recém-aprendido em sala. Durante a resolução dos mesmos, foi solicitada a formação de grupos de quatro a cinco integrantes, na qual os estudantes nunca poderiam repetir os mesmos colegas da equipe de atividades anteriores, em prol da ampliação das relações de coletividade e do incentivo à pluralidade de ideias, ao propor a resolução de problemas lógicos em grupo por indivíduos com distintas perspectivas. Para cada exercício, definiu-se tempo limite de resolução entre três a cinco minutos e caso fosse identificada dificuldade dos estudantes, algumas dicas eram dadas para toda turma. Ao final de cada aula, todos os exercícios propostos eram refeitos pela equipe executora em conjunto com os estudantes e a conversão de pontos por acertos.

Tabela 1. Tabela de gamificação com pontuações por atividade. Fonte: Própria (2020).

\begin{tabular}{ccc}
\hline Atividade & $\mathbf{1 0 0 \%}$ & $\mathbf{5 0 \%}$ \\
\hline Prova OBI (pontos/prova realizada) & 5 & 0 \\
Nota da Prova OBI (pontos obtidos/10) & 40 & 20 \\
Prova Aquecimento OBI (pontos/prova realizada) & 5 & 0 \\
Nota Prova Aquecimento OBI (pontos obtidos/20) & 20 & 10 \\
Frequência (ponto/aula) & 1 & 0 \\
Lista de Exercícios (pontos/lista feita) & 5 & 2,5 \\
Participação em Aula (pontos/participação/aula) & 2 & 1 \\
Desafios (pontos/desafio feito) & 3 & 0 \\
\hline
\end{tabular}

Com o propósito de obter o parecer final dos alunos acerca do curso, bem como compreender sobre o desempenho lógico computacional desenvolvido, elaborou-se um formulário de avaliação composto por 11 questões objetivas e duas subjetivas. $\mathrm{O}$ questionário foi aplicado durante o último encontro com os estudantes, levantando respostas e percepções de um total de 15 discentes. Em seguida, os dados coletados foram tabulados em planilhas eletrônicas por meio da plataforma Planilhas Google, com posterior análise no ambiente Google Collaboratory.

\section{Resultados e Discussão}

Do total de participantes que responderam a avaliação, $60 \%$ foram do sexo masculino e $40 \%$ do sexo feminino. Ao serem indagados em relação a avaliação geral quanto a execução do projeto, pode-se perceber certo nível de aprovação dos estudantes, na qual, a maior parte deles $(93,3 \%)$ declararam estar satisfeitos ou muito satisfeitos.

Quando questionados acerca de sua motivação em participar das atividades, os discentes afirmaram, em maioria, estarem motivados (53,3\%) ou interessados (46,7\%). Não houveram respostas para não motivados, tendo em vista o caráter diferenciado do treinamento em relação a quaisquer disciplinas obrigatórias, bem como reforçando a importância da estratégia gamificada quanto ao método tradicional. Em relação a própria auto-avaliação no projeto, de forma geral, 73,3\% dos alunos responderam estarem satisfeitos ou muito satisfeitos quanto a sua participação.

Por meio das respostas dos acadêmicos ao questionário, verificou-se que 86,7\% 
consideraram que as aulas ajudaram no entendimento de lógica e resolução de problemas. Além disso, $100 \%$ acreditam que o projeto como um todo contribuiu para a aprendizagem de disciplinas que estudam, sendo matemática a mais votada pelos discentes (40,6\%), conforme apresentado na Figura 1.

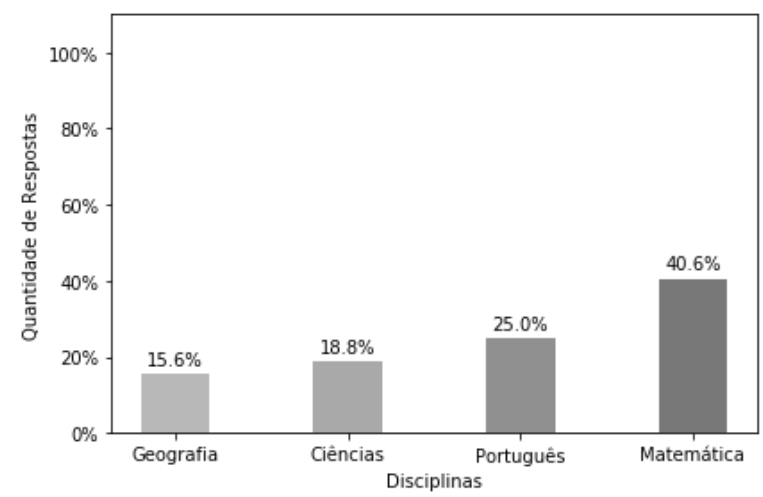

Figura 1. Gráfico das disciplinas com maior contribuição do curso. Fonte: Própria (2020).

Quanto ao domínio dos estudantes referente aos conteúdos trabalhados, todos afirmaram ter aprendido com a execução do curso. Sobre o nível de aprendizado alcançado, 40\% declararam ter aprendido muito, 46,7\% aprendido boa parte e 13,3\% aprendido pouco, entretanto, nenhum respondeu não ter aprendido nada, reiterando a importância dada pelos próprios alunos quanto a inserção do treinamento como parte de sua formação, além da própria experiência e oportunização em competições científicas.

\section{Considerações Finais}

Identifica-se por meio dos dados analisados em relação à avaliação do curso que o projeto configurou-se como uma estratégia promissora para o desenvolvimento de pensamento computacional, fundamentado no domínio atingido pelos participantes ao final do treinamento, bem como pela maioria das assertivas positivas sobre o curso. Outrossim, reforça a efetividade das aulas em decorrência da XXI OBI, classificando 10 estudantes na Modalidade Iniciação para a fase regional e uma estudante na fase nacional, dos quais antes não possuíam conhecimento da olimpíada e em sua primeira participação, figuraram em destaque com outras escolas de tradicional classificação.

Considerando a relação do pensamento computacional com disciplinas do núcleo comum, verificou-se que os próprios discentes compreenderam a transversalidade do conceito, com vistas a auxiliar na compreensão de componentes como a matemática, por desenvolver habilidades similares à de questionamentos matemáticos. Além disso, foi perceptível que a ludicidade promovida por meio dos jogos desplugados e gamificação foram um fator importante para a satisfação dos participantes, visto ser uma forma para atrair a atenção no estudo de pensamento computacional.

Para trabalhos futuros, é importante elevar o tamanho da amostra com mais turmas, desempenhando um comparativo entre abordagens tradicionais e gamificadas, além da elaboração de um teste lógico, a fim de aferir o pensamento computacional entre turmas que participaram e que não participaram do curso, possibilitando a investigação da eficácia da metodologia e do desenvolvimento cognitivo dos alunos. 


\section{Referências}

Aono, A. H., Rody, H. V. S., Musa, D. L., Pereira, V. A., \& Almeida, J. (2017). A Utilização do Scratch como Ferramenta no Ensino de Pensamento Computacional para Crianças. In Anais do XXV Workshop sobre Educação em Computação (pp. 2169-2178). SBC.

Brackmann, C. P. (2017). Desenvolvimento do pensamento computacional através de atividades desplugadas na educação básica. Tese (Doutorado), Programa de Pós-Graduação em Informática na Educação. Porto Alegre, RS: UFRGS, 2017.

Bell, T., Rosamond, F., \& Casey, N. (2012). Computer science unplugged and related projects in math and computer science popularization. In The multivariate algorithmic revolution and beyond (pp. 398-456). Springer, Berlin, Heidelberg.

Brum, M., \& da Cruz, M. (2017). Gamificação para o Ensino de Computação na Educação Básica. In Anais do XXV Workshop sobre Educação em Computação. Porto Alegre: SBC. doi:10.5753/wei.2017.3543.

Martin, S., Cavalheiro, S., Reiser, R., Foss, L., Mazzini, A., Du Bois, A., \& Piana, C. (2018). SoccerCraft: Relato de Atividade para Ensino Aprendizagem de Habilidades do Pensamento Computacional Aplicada no Sexto Ano do Ensino Fundamental. In Anais do XXVI Workshop sobre Educação em Computação. Porto Alegre: SBC. doi:10.5753/wei.2018.3494.

Martins, W. S. (2011). Jogos de Lógica: divirta-se e prepare-se para a Olimpíada Brasileira de Informática. Goiânia: Vieira, 158p.

Oliveira, V., Aranha Junior, J. R., \& Barradas Filho, A. (2019). Aplicação de Métodos Lúdicos para o Desenvolvimento e Avaliação da Capacidade de Pensamento Algorítmico em Crianças. In Anais dos Workshops do Congresso Brasileiro de Informática na Educação (Vol. 8, No. 1, p. 218).

SBC (2017). Referenciais de Formação em Computação: Educação Básica. https://www.sbc.org.br/files/ComputacaoEducacaoBasica-versaofinal-julho2017.pdf, Março, 2020.

Schoeffel, P., Moser, P., Varela, G., Durigon L., Albuquerque, G. D., \& Niquelati, M. D. S. (2015). Uma Experiência no Ensino de Pensamento Computacional e Fomento à Participação na Olimpíada Brasileira de Informática com Alunos do Ensino Fundamental. In Anais do workshop do IV Congresso Brasileiro de Informática na Educação (CBIE 2015) (pp. 1474-1484).

Ribeiro, L. Ensino de Computação na Educação Básica: Diretrizes da SBC. In Computação Brasil, v. 41, p. 6-9, dezembro, 2019.

Werlich, C., Kemczinski, A., \& Gasparini, I. (2018). Pensamento Computacional no Ensino Fundamental: um mapeamento sistemático. In XXIII Congreso Internacional de Informática Educativa (pp. 375-384).

Wing, J. M. (2006). Computational thinking. Communications of the ACM, 49(3), 33-35. 